I

\title{
ResearchArticle
}

\section{Screening of sesame (Sesamum indicum L.) genotypes for yield components under AICRP testing}

\author{
N. Sabitha, K. Navya Jyothi and P. Rajasekhar
}

\section{SUMMARY}

Higher variability for plant height, capsules/plant and seed yield/plant and medium variability for days to 50 per cent flowering and days to maturity was recorded. The variability was low for capsule length among the genotypes. The high yield genotypes viz., GT 4, YLM 66, RMT 377, SI-199-2-84 were also found superior for number of capsules/plant and capsule length while JTS-8 with higher seed yield recorded more number of capsules/plant. DS 45 was found to be early in flowering and maturity.

Key Words : Sesame genotypes, Maturity, Capsules, Seed yield

How to cite this article : Sabitha, N., Jyothi, K. Navya and Rajasekhar, P. (2020). Screening of sesame (Sesamum indicum L.) genotypes for yield components under AICRP testing. Internat. J. Plant Sci., 15 (1): 52-54, DOI: 10.15740/HAS/IJPS/15.1/52-54, Copyright@ 2020: Hind Agri-Horticultural Society.

Article chronicle : Received : 07.11.2019; Revised : 10.12.2019; Accepted : 25.12.2019

\section{$\longrightarrow$ MEMBERS OF THE RESEARCH FORUM}

Author to be contacted :

N. Sabitha, Regional Agricultural Research Station, Tirupati (A.P.)

India

Email : nsabitha84@gmail.com

Address of the Co-authors:

K. Navya Jyothi and P. Rajasekhar, Regional Agricultural Research Station, Tirupati (A.P.) India 